\title{
EFFECTS OF PLASMA ON PGI, RELEASE FROM PROLONGED PERFUSED CANINE VEINS
}

\author{
Jan S Brunkwall, MD*, James C Stanley, $\mathbf{M D}^{\mathrm{t}}$, Linda M Graham, $\mathrm{MD}^{\mathrm{t}}$, \\ William E Burkel, $\mathrm{PhD}^{* *}$ and David Bergqvist, $\mathrm{MD}, \mathrm{PhD}^{*}$ \\ From the Department of Surgery, University of Lund, \\ Malmö General Hospital, Malmö, Sweden*, \\ and the Section of Vascular Surgery, Department of Surgery ${ }^{t}$, \\ and the Department of Anatomy and Cell Biology**, \\ University of Michigan Medical School, Ann Arbor, Michigan, USA
}

(Received 19.12.1989; accepted in revised form 2.4.1990 by Editor U. Abildgaard)

\begin{abstract}
Prostacyclin release from endothelial cells in culture appears increased by the presence of plasma, but occurrence of a similar phenomenon in intact vessels has not been established. In the present investigation release of 6-keto-PGF ${ }_{1}$, the stable breakdown product of prostacyclin, was quantitated from dahine veins perfused ex vivo for 15 minute periods, using three different perfusates: 1) Hank's balanced salt solution (HBSS), 2) $20 \%$ platelet poor plasma (PPP) derived from heparinized blood, in HBSS, and 3) $20 \%$ PPP in HBSS with added arachidonic acid (AA). No differences in initial 6-keto-PGF release existed among the three perfusates. However, PPP and PPP + AA solutions were associated with lesser declines in release, than occurred with HBSS alone, these differences being statistically significant after $60 \mathrm{~min}$ of perfusion $(p<0.05)$. When PPP derived from heparinized and citrated blood rather than from only heparinized blood was used, there was a significantly lower release of prostacyclin $(p<0.05)$. The latter may be due to citrate binding of calcium. These data indicate that autologous plasma does not alter initial prostacyclin release from freshly harvested canine veins, but that it weakens the decline in release usually following prolonged periods of perfusion.
\end{abstract}

\section{INTRODUCTION}

Depressed in vitro production and release of prostacyclin from cultured endothelial cells exposed to salt solutions has been thought to be due to lack of substrate as well as an effect of free radicals. Plasma has been suggested to process a free radical scavenging effect in addition to supplying substrate. On the other hand, human platelet poor plasma (PPP) is known to increase release of prostacyclin from cultured

Key words: plasma, heparin, citrate, perfusion, veins, prostacyclin 
endothelial cells derived from pig aorta (1), bovine aorta (2), human umbilical vein (2), rat smooth muscle cells (3), and rat aorta (4). In most reported studies of this phenomenon, heterologous plasma has been utilized, and in some studies homologous plasma has been used, but there are no reports on the effect of autologous plasma. Many earlier experiments utilized in vitro systems with cells cultured for extensive time periods, a factor that might alter their metabolic activity compared to intact fresh vessels.

Data from studies using rabbit aorta, perfused for 6 min with PPP, have not demonstrated a stimulatory effect of PPP on prostanoid release (5). Plasma, in fact, when compared to incubation in a buffered solution has been shown to decrease the initial release of prostacyclin from rat smooth muscle cells, whereas with repeated exposure it increases release compared to incubation in a buffered solution (6). The aim of this study was to investigate the heretofore unreported effect of autologous plasma on prostacyclin release from freshly harvested canine veins subjected to ex vivo perfusion. Furthermore, to study if there is a difference between plasma derived from citrated blood and plasma derived from only heparinized blood.

\section{MATERIALS AND METHODS}

Adult mongrel dogs $(n=14)$ were anesthetized with pentobarbital $(20 \mathrm{mg} / \mathrm{kg})$, intubated, and mechanically ventilated. Animal care was carried out in accordance with "Principles of Laboratory Animal Care" and "Guide for the Care of and Use of Laboratory Animals" (NIH Publication No. 80-23, revised 1985). External jugular veins, exposed through a midline neck incision after animals had been anticoagulated with heparin $(500 \mathrm{IU} / \mathrm{kg})$, were carefully dissected, with all branches ligated before their excision. These veins were flushed with calcium and magnesium free Hank's balanced salt solution, HBSS-CMF, (Gibco Laboratories, Grand Islands NY, pH 7.4, $290 \mathrm{mOsm}$ ) at $20{ }^{\circ} \mathrm{C}$ until the effluent was clear. Excised veins retracted to approximately half their in situ length. Each vein was divided into $3 \mathrm{~cm}$ long segments and stored briefly in HBSS-CMF prior to being placed in a perfusion device described in earlier publications $(7,8)$. Mounted veins were extended to their original in situ length. The effect on prostanoid release from freshly harvested veins exposed to plasma derived from only heparinized blood $(n=6)$ and plasma derived from heparinized and citrated blood $(n=8)$ were studied. Platelet poor plasma was prepared from blood drawn into containers with or without $3.8 \%$ sodium citrate. Blood was centrifuged at $1800 \mathrm{~g}$ for $20 \mathrm{~min}$ at $20^{\circ} \mathrm{C}$, the plasma supernatant was decanted into polypropylene tubes, being diluted with HBSS to a final concentration of $20 \%$. The diluted PPP was then corrected to a $\mathrm{pH}$ of 7.4. Platelets in these solutions were sparse, and never exceeded $5000 / \mathrm{ml}$.

Perfusion Technique: Control segments were perfused with HBSS for five $15 \mathrm{~min}$ periods at $37^{\circ} \mathrm{C}$. Perfusates ( $25 \mathrm{ml}$ for each period) were changed after each period and stored at $-70^{\circ} \mathrm{C}$ until subsequent prostanoid radioimmunoassay (RIA). Arachidonic acid, AA, was weekly freshly made and dissolved in HBSS. AA was added to the fifth and last perfusate at a concentration of $4 \mu \mathrm{g} / \mathrm{ml}$. Normal venous pressure and flow patterns were simulated with a perfusion pressure of $7 \mathrm{mmHg}$ and nonpulsatile flow of $90 \mathrm{ml} / \mathrm{min}$. The exact length and width of the vein exposed to the perfusate solution was measured, the luminal surface calculated, and prostanoid production data were normalized to surface area.

Radioimmunoassay: All prostanoid RLAs were undertaken in duplicate. Different assays were performed for samples from segments perfused with citrated and heparinized plasma versus those perfused with heparinized plasma. Prostanoids were extracted from the samples according to a modification of the method described (9). Briefly, acetonitrile was added to the perfusate to precipitate proteins that were then discarded. The supernatant was then acidified with formic acid and mixed with ether to remove the lipids. The prostaglandins were then extracted three times into ethyl acetate, dried in air, and redissolved in $0.1 \%$ porcine skin gelatine phosphate-buffered saline. 
Prostacyclin was measured as the stable degradation product 6-keto-PGF a commercial RIA kit (New England Nuclear, Boston, MA). This method employs overnight incubation of ${ }^{3} \mathrm{H}$ labelled 6-keto-PGF ${ }$ and a test sample with a constant amount of specific antibody raised against a bovine $\$ \mathbb{S}_{\text {rum }}$ albumin conjugate. The bound 6-keto-PGF ${ }_{1}$ was subsequently absorbed by activated charcoal suspension. The supernatant was then subjected to liquid scintillation for quantitation of beta activity. These data were compared to those from freshly made standard dilutions of 6-keto-PGF ${ }_{10}$ present in the test sample and were subjected to computer analysis with a progranfme for radioimmunoassays. The percentage cross reactivity towards other prostaglandins was: PGE, 2.5, PGF $10.3, \mathrm{PGF}_{2} 0.05$ and $\mathrm{TxB}_{2}<0.3$ (manual, New England Nuclear).

Tiromboxane was measured as its stable degradation product $\mathrm{TxB}_{2}$ with RIA similar to that described above also using ${ }^{3} \mathrm{H}$ labelled tracer. The crossreactivity towards other prostaglandins was: $\mathrm{PGD}_{2} 1.0, \mathrm{PGD}_{1} 0.32, \mathrm{PGF}_{10} 0.04$ and $\mathrm{PGF}_{2} 0.04$ (10).

Prostanoid release in this report is expressed $15 \mathrm{pg} / \mathrm{mm}^{2}$ surfatce area/15 min. Data is presented as mean \pm 1 SEM. Wilcoxon signed rank test was used to assess the presence of statistically significant differences.

Morphology: After perfusion, specimens were prepared for scanning electron microscopy (SEM), by fixation in $2.5 \%$ glutaraldehyde in $0.1 \mathrm{M}$ cacodylatebuffer at a pressure of $7 \mathrm{mmHg}$. Veins segments were dehydrated in ethanol, incubated for $10 \mathrm{~min}$ in hexamethyldisilazane, and dried in air, after which they were sputter-coated with gold-palladium (ll).

\section{RESULTS}

Recovery of added 6-keto-PGF $1 \alpha$ after extraction was $75 \pm 5 \%$. $2^{6-k e t o-P G F}$ level in diluted plasma before perfusion was $65 \pm 22 \mathrm{pg} / \mathrm{ml}\left(\approx 4 \mathrm{pg} / \mathrm{mm}^{2}\right)$ and in each case the measured plasma value was subtracted from the value obtained after perfusion.

PPP derived from heparinized, citrated blood (Fig 1) Vein segments perfused with PPP or PPP + AA derived from citrated blood exhibited a dramatically lower initial release of 6-keto-PGF $(p<0.05)$ compared to HBSS perfusion alone. This effect declined over time, such that after $45 \mathrm{~min}$ perfusion, no statistically significant difference existed. Addition of AA to the last perfusate caused a dramatic increase in release of

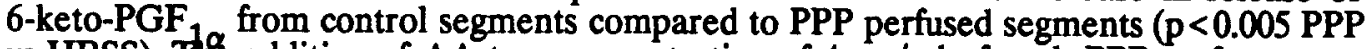
vs HBSS). The addition of AA to a concentration of $4 \mu \mathrm{g} / \mathrm{ml}$ of each PPP perfusate was not associated with further increase of the release of prostacyclin. On the contrary, a slight but significant increase was seen when AA was added to the last PPP perfusate $(\mathrm{p}<0.01)$.

PPP derived from only heparinized blood (Fig 2) Perfusion with heparin-derived PPP with or without added AA did not alter the initial release compared to HBSS perfusion. However, after prolonged perfusion, there was a tendency to greater 6-keto-PGF release from PPP or PPP + AA perfusions compared to HBSS perfusions. This differeffce became statistically significant after $60 \mathrm{~min}(\mathrm{p}<0.05)$. AA added to the last perfusate caused an eleven fold increase of prostacyclin from segments perfused with HBSS $(p<0.001)$, whereas prostacyclin release from PPP perfused vessels increased only twofold $(\mathrm{p}<0.05)$. A decrease in 6-keto-PGF $1 \mathrm{~g}$ release occurred when veins were perfused with PPP + AA, but there was no response to the last addition of $A A$ in this setting. Differences did not exist in 6-keto-PGF $1 \alpha$ release between segments perfused with PPP
or PPP + AA.

Morphology: $75-90 \%$ of the endothelial cells were still present after perfusion. No difference was found between the various protocols studied. Scattered platelets were seen, but no platelet aggregates. 


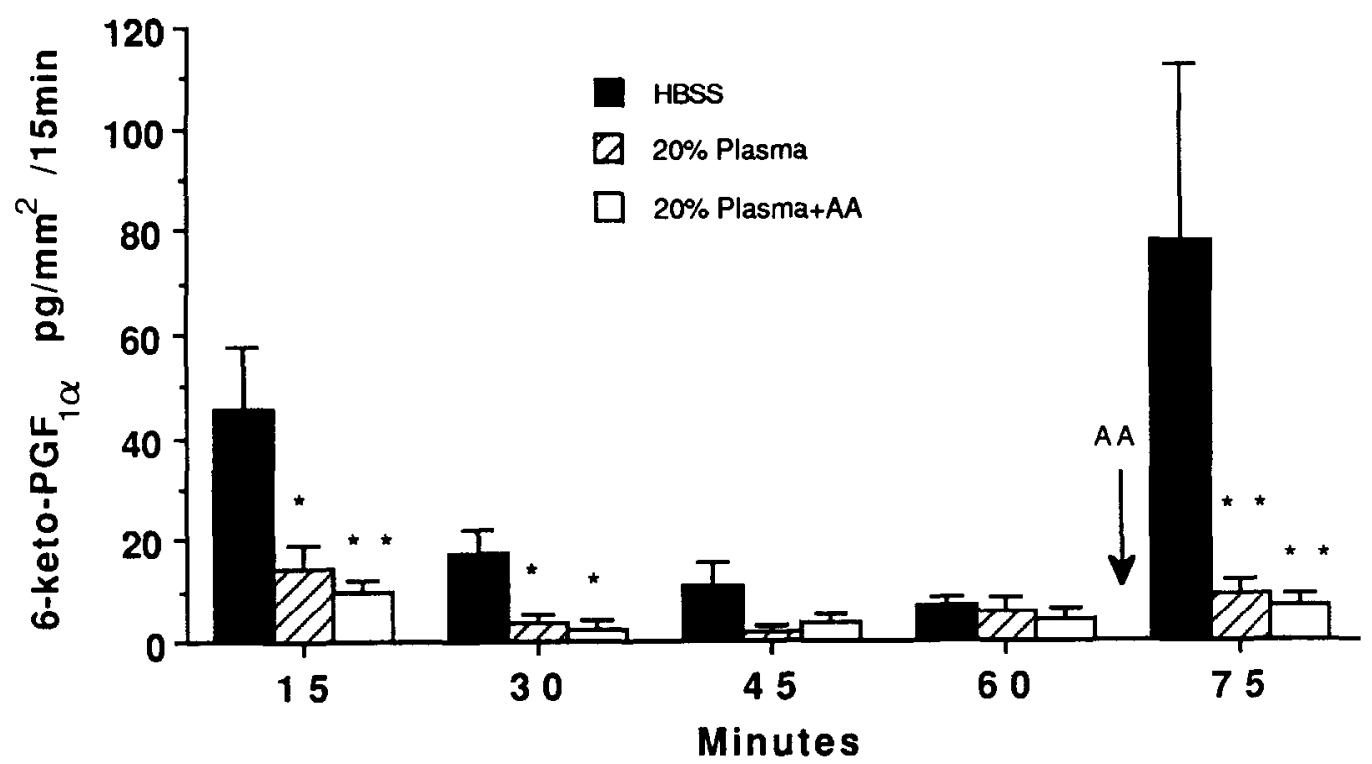

EIG 1. Effect of $20 \%$ platelet poor plasma derived from heparinized and citrated blood in the perfusate compared to perfusion with Hank's Balanced Salt Solution. Means + SEM N=8 in each group. $A A=$ addition of Arachidonic Acid $(4 \mu \mathrm{g} / \mathrm{ml})$. Perfusion pressure $7 \mathrm{mmHg}$ and mean flow $90 \mathrm{ml} / \mathrm{min} . *=p<0.05$ vs controls, $"=p<0.01$ vs controls (Wilcoxon signed rank test at the same measure point).

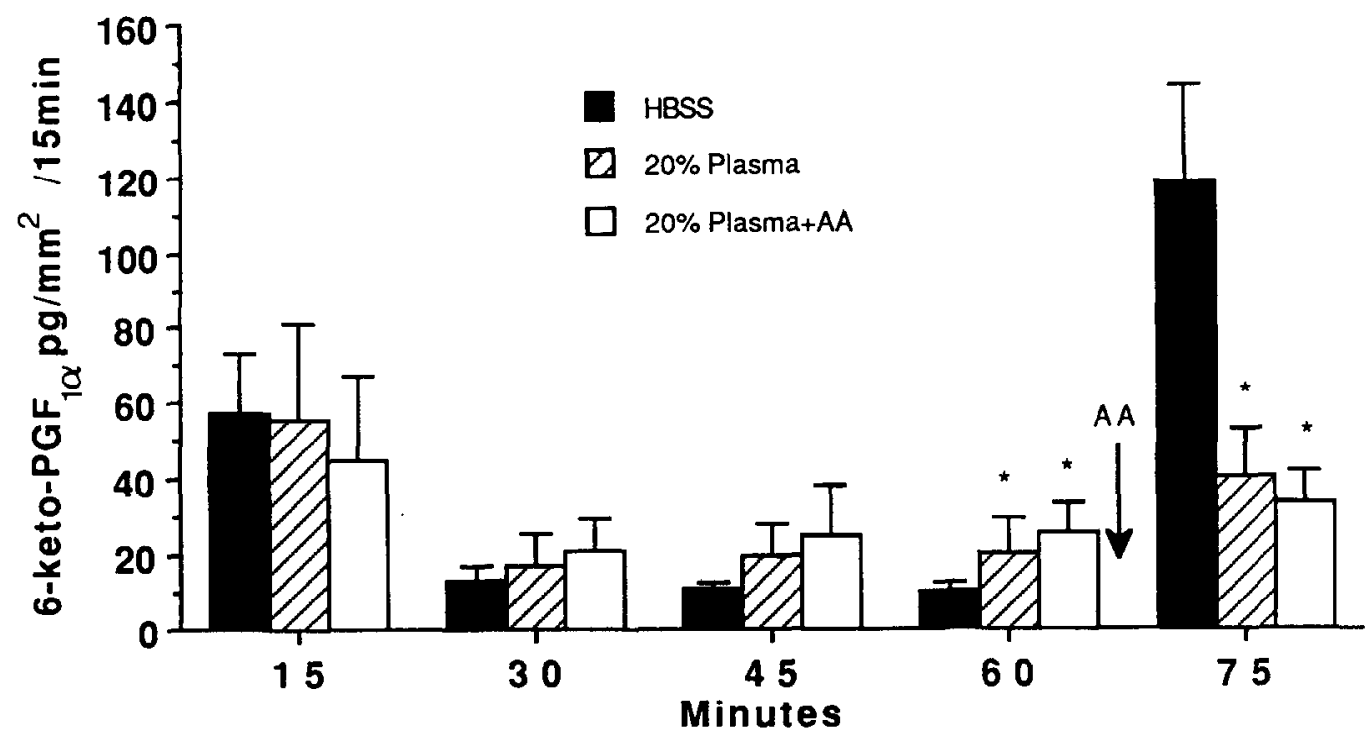

EIG 2. Effect of $20 \%$ platelet poor plasma derived from only heparinized blood in the perfusate compared to perfusion with Hank's Balanced Salt Solution. Means + SEM, $N=6$ in each group. $A A=$ addition of Arachidonic $A$ cid $(4 \mu \mathrm{g} / \mathrm{ml})$. Perfusion pressure $7 \mathrm{mmHg}$ and mean flow $90 \mathrm{ml} / \mathrm{min} . " p<0.05$ vs controls, $" \mathrm{p}<0.01$ vs controls (Wilcoxon signed rank test at the same measure point). 


\section{DISCUSSION}

The stimulation effect of plasma on prostacyclin releases has been attributed by some to the presence of a still not fully identified prostacyclin stimulating plasma factor, PSPF $(4,12)$. This factor is reported to be non-dialysable and present in a 10,000 Dalton eluent fraction. Others have suggested that plasma, in a not yet completely clarified manner, may act as a free radical scavenger $(3,13)$. Such a scavenging effect might prevent an irreversible blockage of cyclooxygenase that otherwise occurs with AA perfusion. Dejana and Vergara-Dauden observed that rat smooth muscle released more prostacyclin upon repeated addition of AA if human plasma was present, than with repetitive AA exposure alone $(3,13)$. In these latter studies the AA dose was approximately 100 fold higher than in our experiment, a difference that might account for the variance in our results. AA binds to albumin (14) and can also be incorporated in HDL particles $(15,16)$. Thus, AA given in lower doses may be preferentially bound to plasma proteins, rather than being extracted by endothelial cells and converted to 6keto-PGF 1. This might explain, in part, why we did not observe a higher initial release of prostacyclin when AA was added to PPP, and why there was a lesser response to AA added to the last perfusate.

The current investigation establishes that the immediate response to perfusion is not altered by the presence of heparin derived PPP compared to HBSS, but that the decline in release with time is lessened in the presence of plasma. The reason for this is not clear, but it is hypothesized that plasma albumin bound AA or AA present in lipoproteins, i e HDL, LDL, which are very rich in arachidonate and known to stimulate PGI, synthesis $(11,17)$ may be slowly released and utilized by the endothelial cells. This effect of plasma is more pronounced after longer perfusion, i e 75 vs $60 \mathrm{~min}$. In an earlier study we reported that thrombin, bradykinin, and AA given at the end of perfusion with buffer caused increased release of prostacyclin (18). The effect of AA on prostacyclin production is lessened in the presence of plasma. When AA was given as a bolus after 60 min to HBSS-perfused segments, an increased prostacyclin release was seen, but when given to plasma-perfused segments only a slight increase was seen. Furthermore, the addition of AA to plasma perfusates already at the first perfusion, did not increase the prostacyclin release, an effect seen in HBSS-perfused segments (18). This implies that AA is preferentially bound to plasma proteins than being incorporated into endothelial cells. This supports the tenet that decreased prostacyclin release occurring over time in vessels perfused with HBSS or plasma is unlikely related to cyclooxygenase inhibition, but may be due to an inhibition of phospholipase or alteration of its membrane receptors. Another possible explanation for plasma's effect over time is that it contains free calcium which stimulates the production of prostacyclin (19). The facts that calcium is needed for the action of phospholipase, and that calcium will be bound to citrate $(20,21)$, may explain why prostacyclin release was lessened when citrated blood was used to derive PPP. This is in agreement with Taylor who found that excess of sodium citrate abolished the response upon calcium stimulation (19). It is tempting to speculate that additional plasma increases the availability of substrate for prostacyclin production, more than scavenging cyclooxygenase, so explaining the increased release of prostacyclin after prolonged perfusion i e $60-75 \mathrm{~min}$.

In experiments using cultured endothelial cells, others have found increased prostanoid release with exposure to heterologous or homologous plasma (22-24). In the present investigation there was no increased initial release when veins were perfused with plasma compared to perfusion with HBSS. This discrepancy with our results may be explained by the fact that we used autologous plasma, and that our system involved study of in situ endothelial cells. Others have used non-autologous plasma, that might be immunologically active (25), and cultured cells that might have altered metabolic responsiveness.

\section{ACKNOWLEDGEMENT}

This study was in part supported by the Swedish Medical Research Council 00759. 


\section{REFERENCES}

1. SEID JM, JONES PBB, HUGHES P and RUSSEL RCG. Stimulation of prostacyclin production from vascular endothelial cells by plasma, serum and platelets under normal and pathological conditions. Agents Actions. 11, 83-92, 1982.

2. TREMOLI E, JAFFE EA, GOLDMAN KT and WEKSLER B. Prostacyclin production by endothelial cells. Effects of sera from normal and hyperlipidemic subjects. Arteriosclerosis. (2), 178-185, 1985.

3. VERGARA-DAUDEN M, BALCONI G, BREVIARIO F, CHIABRANATO C, DE GAETANO G and DEJANA E. Further studies on the mechanism of action of human plasma in stimulating prostacyclin production by rat smooth muscle cells. Thromb Haemost. 530, 372-376, 1985.

4. POLTERAUER P, SINZINGER H, PESKAR BA. Prostacyclin synthesis stimulating plasma factor in patients with different stages of hepatic coma. Prostaglandins Leukotrienes Med. 13, 315-321 1984.

5. GALLI C, PETRONI A, SOCINI A, AGRADI E, COLOMBO C, FOLCO GC and TREMOLI E. Platelet vessel wall interactions: Effects of platelets and plasma on the antiaggregatory activity and 6-keto-PGF $1 \alpha$ production in isolated perfused aortas. Prostaglandins. 22, 703-713, 1981.

6. TODISCO A, DECKMYN H, D'HONDT L, ZOJA C and VERMYLEN J. The prostacyclin stimulating plasma factor PSPF protects endothelial cells from exhaustion. Thromb Haemost. 50, 242, abstract 0758, 1983.

7. BRUNKWALL JS, STANLEY JC, GRAHAM LM and BURKEL WE: Influence of pressure, flow rate, and pulsatility on release of 6-keto-PGF 1 and thromboxane $\mathrm{B}_{2}$ in ex vivo-perfused canine veins. J Vasc Surg. 7, 99-107, 1988.

8. BRUNKWALL JS, STANLEY JC, GRAHAM LM, BURKEL WE and BERGQVIST D: Arterial 6-keto-PGF ${ }_{1}$ and $\mathrm{TxB}_{2}$ release in ex vivo perfused canine vessels: Effects of pulse rate, pullsatility, aftered pressure and flow rate. Eur J Vasc Surg. 3, 219-225, 1989.

9. SIMMONS PM, SALMON JA and MONCADA S. The release of leukotriene $\mathrm{B}_{4}$ during experimental inflammation. Biochem Pharmacol. 32, 1353-1359, 1983.

10. FITZPATRICK FA, GORMANA RR, MCGUIRE JC, KELLY RC, WYNALDA $M A$ and SUN FF. A radioimmunoassay for thromboxane $B_{2}$. Anal Biochem. 82: 1-7, 1977.

11. NATION JL. A new method using hexamethyldisilazane for preparation of soft insect tissues for scanning electron microscopy. Stain Technol. 68, 347-351, 1983.

12. REMUZZI G, LIVIO M, CAVENAGHI AE, MARCHESI D, MECCA G, DONATI MB and DE GAETANO G. Unbalanced prostaglandin synthesis and plasma factor in uremic bleeding. Thromb Res. 13, 531-536, 1978.

13. DEJANA E, PROSDOCIMI $M$ and DE GAETANO G. Regulation of prostacyclin production by vascular cells in in vitro and in vivo experimentals system. Wiener Klinische Wochenschrift. 98(7), 206-208, 1986. 
14. FLEISHER LN, TALL AR, WITTE LD, MILLER RW and CANNON PJ. Stimulation of arterial endothelial cell prostacyclin synthesis by high density lipoproteins. J Biol Chem. 57(12), 6653-6655, 1982.

15. BROX JH and NORD $\varnothing Y$ A. The effect of polyunsaturated fatty acids on endothelial cells and their production of prostacylin, thromboxane and platelet inhibitory activity. Thromb Haemost. (50), 762-767, 1983.

16. NORD $\varnothing Y$ A, SVENSSON B and HOAK JC. The effects of albumin bound fatty acids on platelet inhibitory function of human endothelial cells. Eur J Clin Invest. 2. 5-10 1979.

17. SPECTOR AA, SCANN AM, KADUCE TL, FIGARD PH, FLESS GM and CZERVIONKE RL. Effect of human plasma lipoproteins on prostacyclin production by cultured human endothelial cells. J Lipid Res. 6. 288-297, 1985.

18. BRUNKWALL JS, STANLEY JC, KRESOWIK TF, GRAHAM LM, BURKEL WE and BERGQVIST D. Prostanoid release from ex vivo perfused canine arteries and veins: Effects of prolonged perfusion, intermittent perfusion, as well as exposure to exogenous arachidonic acid, thrombin and bradykinin. Thromb Haemost. (In Press).

19. TAYLOR GW, CHAPELL CG, FRAZER CE and RJTTER JM. Prostacyclin synthesis by vascular tissue. Effect of extracellular $\mathrm{Ca}^{27}$. Biochem J. 239, 237-239, 1986.

20. POYSER NL Effect of using calcium-free Krebs' solution on basal and A 23187stimulated prostaglandin output from the day 15 guinea pig uterus superfused in vitro. Prostaglandins Leukotrienes Med. 13, 259-269, 1984.

21. RITTER JM, FRAZER CE and TAYLOR GW. pH dependent stimulation by $\mathrm{Ca}^{2+}$ of prostacyclin synthesis in rat aortic rings: Effects of drugs and inorganic ions. Br J Pharmacol. 21, 439-446, 1987.

22. MCINTYRE DE, PEARSON JD and GORDON JL Localization and stimulation of prostacyclin production in vascular cells. Nature. 217, 549-551, 1978.

23. SEID JM, JONES PBB and RUSSEL RGG. The presence in normal plasma, serum and platelet sof factors that stimulate the production of prostacyclin $\mathrm{PGI}_{2}$ by cultured endothelial cells. Clin Sci. 64, 387-394, 1983.

24. AVIRAM M, BROX J and NORD $\varnothing Y$ A. Effects of postprandial plasma and chylomicrons on endothelial cells. Acta Med Scand. 219, 341-348, 1986.

25. GOLDSMITH JC and MCCORMICK JJ. Immunologic injury to vascular endothelial cells: Effects on release of prostacyclin. Blood. 63(5), 984-989, 1984. 